Conclusion Regular nitrous oxide abuse causes an active vitamin B12 deficiency; usually total vitamin B12 is normal and more sensitive markers including homocysteine, methylmalonic acid (MMA) and active vitamin B12 are needed for diagnosis. Nitrous oxide abuse is commonplace amongst teenagers and young adults, it is important that paediatricians are made aware of how commonly it is abused and the neurological consequences. Nitrous oxide is cheap and easy to obtain; particularly as it can be bought legally for whipping cream. Those abusing it regard nitrous oxide to be a safe legal high and a thorough drug history is needed to recognise abuse, consideration should also be made for patients requiring recurrent nitrous oxide for medical procedures and pain relief.

\section{G71(P) ABSTRACT WITHDRAWN}

\section{G72(P) ANOTHER TUBE IN SCROTUM: AN UNUSUAL CAUSE OF HYDROCELE}

${ }^{1} \mathrm{~L}$ Rehman, ${ }^{1} \mathrm{M}$ Kamal, ${ }^{2} \mathrm{M}$ Piracha, ${ }^{2} \mathrm{~B}$ Power, ${ }^{3} \mathrm{M}$ Shahid. ${ }^{1}$ Paediatric Emergency Department, Tallaght University Hospital, Dublin, Ireland; 'Paediatric Department, Letterkenny University Hospital, Letterkenny, Ireland; ${ }^{3}$ Paediatric Department, Portiuncula University Hospital, Ballinasloe, Ireland

\subsection{6/archdischild-2020-rcpch.53}

Aim To report a case of a child presented with unilateral scrotal pain and hydrocele.

Method 27 months old boy with known background of hydrocephalus, mild global delay and chromosomal deletions, had his VP shunt inserted 7 months ago. He presented in emergency department with one day history of vague symptoms of right scrotal pain and swelling. It was noticed by his mother while giving bath who also felt some tube like consistency in the upper part of right scrotum.

Physical Examination revealed a well looking boy who wasn't in any distress/pain with a CRT $<2$ sec. His vitals were normal for his age.

Systemic examination was unremarkable apart from mild right sided hydrocele and coiled tube in the right scrotum. He was reviewed by surgical team to $\mathrm{R} / \mathrm{O}$ right sided torsion. Impression was VP tube in Right Scrotum which was confirmed by $\mathrm{x}$-ray pelvis. He was transferred to tertiary care surgical team for Elective hernioplasty.

Results VP shunt tip in scrotum is among rare complication of procedure as in our case. ${ }^{1}$ Far end of tube in peritoneum goes in and out of scrotum via patent processus vaginalis and could be felt on examination. ${ }^{1} 2$

Conclusion Surgical exploration and bilateral hernioplasty is mandatory to prevent testicular torsion and other potential complications. $^{1-3}$

\section{REFERENCES}

1. Albala DM, Danaher JW, Huntsman WT. Ventriculoperitoneal shunt migration into the scrotum. Am Surg 1989 (11);55:685-688.

2. Alonso-Vanegas M, Alvarez JL, Delgado L, Mendizabal R, Jimenez $J$, SanchezCabrera JM. Gastric perforation due to ventriculo-peritoneal shunt. Pediatr Neurosurg, (1994);21:192-194.

3. Agarwal T, Pandev S, Niranian A, Jain V, Mishra S, Agarwal V. Unusual complication of ventriculoperitoneal shunt surgery. Pediatr Neurosci 2009(2);4:122-123.

\section{G73(P) NEUROCYSTICERCOSIS IN A 9 YEARS OLD GIRL WITH FIRST EPISODE OF FOCAL SEIZURES - A REPORT FROM DUBAI}

K Gengaimuthu. Department of Paediatrics, International Modern Hospital, Dubai, UAE

\subsection{6/archdischild-2020-rcpch.54}

Background 50\% of afebrile epileptic seizures in children are symptomatic resulting from an underlying cause. Neurocysticercosis (NCC) accounts for more than 50\% cases of partial epilepsy in some series. Reported cases of NCC are very rare in Gulf region as consumption of pig meat is restricted and slaughterhouses are effectively supervised. Herein we present a 9 years old girl with first episode of focal status epilepticus who was diagnosed as NCC and successfully managed in our hospital.

Case Report This 9 years old girl presented with focal tonic clonic seizures involving right upper limb and conjugate gaze deviation to right side at home and in another hospital many such episodes recurred despite IV diazepam and hence she was referred to us. Seizures were controlled with IV phenytoin infusion followed with oral oxcarbamazepine. Magnetic Resonance Imaging (MRI) brain done at 15 hours post admission revealed a ring enhancing lesion on the left temporo-occipital lobe with surrounding edema that was consistent with neurocysticercosis. Electroencephalography (EEG) was abnormal with persistent delta range activity noted in the left occipito parietal region. She received a 21 days course of oral albendazole $(25 \mathrm{mg} / \mathrm{kg} / \mathrm{day}$ in 2 doses $)$ under cover of steroids initially for 7 days. Follow up MRI scan 6 months later revealed resolution of edema and a significant decrease in the size of initial ring lesion. Her anticonvulsant therapy was discontinued after a year of uneventful follow up.

Discussion Neurocysticercosis is widely prevalent in many developing countries including India, Latin America, Sub Saharan Africa and South East Asian region. 10 - 20\% of general population showed residual brain parenchymal lesions in CT imaging in Peru and Honduras. More than 5 million cases of preventable epilepsy worldwide are causally related to NCC. Albendazole treatment for 2 to 3 weeks was found to hasten the resolution of NCC and also achieve better seizure control. Ours is only the second reported case of NCC from this Gulf region, the previous one having been a 4 years old Indian girl with transient loss of vision (ictal amaurosis) due to a solitary occipital NCC.

\section{G74(P) AUDIT OF PREGNANCY PREVENTION PROGRAMME (PPP) COMPLIANCE IN VALPROATE PRESCRIBING IN FEMALE PAEDIATRIC PATIENTS}

${ }^{1} \mathrm{~A}$ Barker, 'S Daniels, ${ }^{2} \mathrm{P}$ Harijan. 'Paediatrics, Peterborough City Hospital, North West Anglia Trust, Peterborough, UK; ${ }^{2}$ Paediatric Neurology department, Addenbrookes, Cambridge University Hospital, Cambridge, UK

\subsection{6/archdischild-2020-rcpch.55}

Introduction Taking valproate during pregnancy can cause serious birth defects, 1 out of 10 children will have physical defects and 3 to 4 out of 10 will have early developmental problems potentially leading to significant learning disabilities. In April 2018 the Medicines and Healthcare products Regulatory Agency (MHRA) released guidelines stating, 'Valproate must no longer be prescribed to Women or girls of childbearing potential unless they are on the Pregnancy Prevention 